\title{
Compliance with a class teaching breast self examination
}

\author{
M W CALNAN, J CHAMBERLAIN, AND S MOSS \\ From the Section of Epidemiology, Institute of Cancer Research, Sutton, Surrey SM2 5PX, UK
}

\begin{abstract}
SUMMARY As part of the evaluation of a class teaching breast self examination (BSE), a sample of women were interviewed shortly before they were invited to attend the class and again one year later. A comparable sample in a different "control" district were interviewed twice in the same way. The interviewers inquired about the practice of breast self examination (BSE) and about beliefs about breast cancer. The findings enable changes in behaviour and beliefs among those who attended and did not attend the class and among women in the control district during the same year to be compared. Women who attended the class showed a more pronounced improvement in BSE practice compared with non-attenders and with the control group. The improvement was in BSE technique rather than the frequency with which it was carried out.
\end{abstract}

A comparative trial to examine the relative impact of different forms of early detection programmes on breast cancer morbidity and mortality rates is in progress in the United Kingdom. ${ }^{1}$ One method of early detection of breast cancer is breast self examination (BSE); classes are provided in two of the trial districts to teach women how to carry it out effectively and on a regular basis. It is postulated that regular BSE will facilitate the early detection of breast abnormalities, and that once an abnormality is identified women will promptly seek professional medical help.

The success of any early detection measure is dependent on achieving a high compliance rate. Compliance in this context refers to attendance at a class, continued adherence thereafter to regular breast self examination following the recommended technique, and prompt seeking of professional medical help once an abnormality is detected.

The major aim of this study was to examine the impact that the education given at the class had on behaviour; changes in women's beliefs and feelings were also examined, since raising awareness about breast self examination and identification of breast abnormalities may be all that is required to facilitate early detection. Also, whereas behaviour may change as a result of education women may still be uncertain about the value of BSE or doubtful about their ability to detect an abnormality. Finally, the practice of BSE may increase women's feelings of anxiety and fear about breast cancer which may be negative in its own right but may also have consequences for the women's response when they identify breast abnormalities in themselves. ${ }^{2}$

\section{Method}

The study was carried out in two health districts? included in the main trial, ${ }^{1}$ both in large provincial cities in England. All women aged between 45 and 64 registered with general practitioners serving each district are included in the trial. In one district each woman was invited to attend a class teaching BSE held in a hospital in the centre of town. The class consisted of a short instructional film and a talk by a nurse, followed by a discussion. In the second "control" district no such facility or any other form of breast screening was provided other than conventional diagnostic facilities. During the course of this study no local health education campaigns were carried out in the control district on this topic.

Random samples of women were selected from the age/sex registers of all general practitioners serving the BSE district $(n=1150)$ and the control district $(n=1105)$. Comparison of the sociodemographic characteristics of women in the two samples showed that women in the control district were more likely than women in the BSE district to be older, to have had longer formal education, and to come from backgrounds where the head of the household was in a non-manual occupation (table 1).

The sample of women in the BSE district were 
interviewed in their own home in autumn 1980, about one month before they received an invitation to attend the BSE class. Those women who were successfully interviewed were then approached a year later and reinterviewed. Two stages of interviewing also took place in the control district at the same times as in the BSE district. Respondents at the first stage did not know that they were to be reinterviewed. Data on whether women in the BSE district had attended the class were derived from information collected in the main trial.

Table 1 Sociodemographic characteristics of the samples of women selected from the BSE district and the control district

\begin{tabular}{|c|c|c|}
\hline & $\begin{array}{c}\text { BSE district } \\
(\%)\end{array}$ & $\begin{array}{c}\text { Control district } \\
(\%)\end{array}$ \\
\hline \multicolumn{3}{|l|}{ Social Class } \\
\hline$I+I I$ & 22 & 29 \\
\hline III NM & 16 & 19 \\
\hline III M & 33 & 18 \\
\hline IV and V & 26 & 26 \\
\hline Not classifiable & 1 & 1 \\
\hline \multirow[t]{2}{*}{ Not applicable } & 2 & 7 \\
\hline & $\mathrm{n}=678$ & $\mathrm{n}=738$ \\
\hline \multicolumn{3}{|l|}{ Age: } \\
\hline$<55$ & 51 & 42 \\
\hline$\geqslant 55$ & 49 & 57 \\
\hline \multirow[t]{2}{*}{ Not applicable } & 1 & 1 \\
\hline & $\mathrm{n}=678$ & $\mathrm{n}=\mathbf{7 3 0}$ \\
\hline \multicolumn{3}{|l|}{ Left school at: } \\
\hline 15 or under & 79 & 63 \\
\hline$>15$ & 20 & 36 \\
\hline \multirow[t]{2}{*}{ Not applicable } & 1 & 1 \\
\hline & $\mathrm{n}=678$ & $\mathbf{n}=\mathbf{7 3 8}$ \\
\hline \multicolumn{3}{|l|}{ Marital status: } \\
\hline Single & 5 & 6 \\
\hline Married & 82 & 77 \\
\hline \multirow[t]{2}{*}{ Divorced/separated/widowed } & 13 & 16 \\
\hline & $n=678$ & $n=738$ \\
\hline
\end{tabular}

The interviews were administered by trained interviewers unconnected with the BSE education team and included questions about whether and how often women practised BSE. Those who did so at least once a year were asked about the technique used. An index of technique was made up to four items, each of which was emphasised in the class as being an important element. These items were:

(1) When examining your breasts do you look at them in a mirror?

(2) When examining your breasts do you feel them?

(3) When examining your breasts do you feel under your arms as well?

(4) Do you usually follow a set routine when you examine your breasts?
A "yes" to any of these scored one point and a negative response nil, so that the score ranged from $0-4$ points. Women reporting never having carried out breast self examination automatically scored 0 . There are uncertainties about the validity of using self reported measures of BSE practice, although obtaining more objective information is difficult, and in the circumstances self report might be the only acceptable method. ${ }^{3}$

Data were also collected in both interviews on the proportion of women who had identified breast abnormalities, and whether these abnormalities had been discovered by deliberate BSE.

Women in the BSE district who had ever examined their breasts were asked if they thought they could detect an abnormality if one was there, and also if they were confident that they were performing it properly.

Data on beliefs about the value of BSE were derived from a scale made up of responses to the eight different statements starred in table 2 . This is an extended version of a scale developed and validated by Stillman. ${ }^{4}$ Each item was scored from 1-5 according to the strength of agreement with the statement and the range ran from 5-40, the high

Table 2 Statements about breast cancer and breast self examination used as basis for a scale of perceived value of breast self examination and perceived vulnerability to breast cancer

- (1) If more women examined their breasts regularly there would be fewer deaths from breast cancer.

† (2) My health is too good at present to even consider thinking I might get breast cancer.

- (3) If I found a lump in my breast myself it would not really matter because by then it's too late anyway.

† (4) Whenever I hear of a friend or relative or a public figure getting breast cancer, it makes me realise that I could get it too.

* (5) If I examined my own breasts regularly, I might find a lump sooner than if I went for a check up.

† (6) There are so many things that could happen to me that it is pointless to think about any one thing like breast cancer.

* (7) Even though it is a good idea, I find examining my breasts an embarrassing thing to do.

- (8) Examining my breasts would make me worry unnecessarily about breast cancer.

+ (9) The older I get the more I think about the possibility of getting breast cancer some day.

*(10) I don't examine my breasts because I'm afraid I might find something wrong.

-(11) I don't examine my breasts because I'm not sure I would do it properly.

-(12) Examining my breasts takes too much time or bother.

Each response to a statement was coded either agree strongly, agree a little, neither agree nor disagree, disagree a little, and disagree strongly.

A further question was asked:

$+(13)$ Do you think your chances of getting breast cancer are? greater than most other women about the same less than most other women.

* = Perceived value of breast self examination.

$\dagger=$ Perceived vulnerability to breast cancer. 
scorers being those who placed the greatest value on BSE. The scores were then grouped into four categories, low (30 and under), low to moderate (31-33), moderate to high (34-38), and high (39-40).

Women's beliefs about the value of BSE as well as their willingness to carry it out may also depend on whether they have a positive or negative image of the person who performs it regularly. Respondents were asked if they believed there was a type of person who carried out BSE and if so to describe her; their descriptions were subsequently grouped into positive (sensible, well organised, intelligent) and negative (hypochondriac, neurotic, the worrier).

Data on beliefs about breast cancer were derived from three measures. One measure examined perceived vulnerability to breast cancer and was derived from five statements indicated by a dagger in table 2, based on Stillman's scale. ${ }^{4}$ Each item scored from 1-5 points according to agreement with the statement and the range ran from 5-23, high scorers being those feeling most vulnerable to breast cancer. Scores were classified into low (5-10), medium (11-16), high (17-23) categories. The second measure, examining the extent of concern about breast cancer, was derived from responses to two questions. One asked if there was any particular illness the respondent worried about getting. If she mentioned breast cancer a score of two points was allocated, if any other form of cancer or cancer in general one point, and if no reference to cancer nil points. All respondents were also asked specifically about the extent of their worry about breast cancer. The answers were classified as a lot of worry (two points), to some extent (one point), and not at all (nil). The combined scores ran from 0-4 points and were grouped into low concern (nil), moderate concern (1-2), and very concerned (3-4).

The third measure examined the extent to which each woman thought that she could actually reduce her chances of getting breast cancer, answers being classified into those who thought that they could do nothing or did not know, and those who thought that they could do something.

Table 3 shows the response to interview for the two districts at both stages. Owing mainly to inaccuracies in general practitioner registers the samples

Table 3 Response rate at first and second interviews for the two districts

\begin{tabular}{|c|c|c|}
\hline & BSE district & Control district \\
\hline Random sample & 825 & 895 \\
\hline Responded to 1st interview & $678(82 \%)$ & $738(82 \%)$ \\
\hline Responded to 2 nd interview & $540(65 \%)$ & $594(66 \%)$ \\
\hline
\end{tabular}

originally selected were reduced to 825 in the BSE district and 895 in the control district. One possible confounding factor in the results may be the fact that non-respondents to both first and second interviews were more likely to be non-attenders at the BSE class. There was only a small difference in participation rates at the first stage of the interviewing between attenders $(83 \%)$ and non-attenders $(81 \%)$, although at the second interview this had increased (72\% against $62 \%$, $\mathrm{p}<0 \cdot 01)$.

\section{Results}

PRACTICE OF BREAST SELF EXAMINATION

The most important elements in the practice of BSE are the frequency with which it is carried out and the technique used. Since it is difficult to assess the relative importance of each in enabling identification of breast abnormalities, they have been analysed both separately and combined into one index.

\section{FREQUENCY}

Women were recommended at the education class to carry out breast self examination monthly. Table 4 shows the change in the proportion of women performing it at least once a month between the first and second interviews in each district, and in the class attenders and non-attenders within the BSE district. There was no statistically significant difference between the percentage doing it monthly at the first interview in the three groups. There were, however, statistically significant increases over the one year period in the proportion performing it at least once a month in both districts and within the BSE district, in both non-attenders and attenders. Table 4 also shows changes in the frequency of BSE between first and second interviews. No statistically significant difference was found between the two districts nor between the attenders and non-attenders in the BSE district.

\section{TECHNIQUE}

Those scoring three or more points on the measure of BSE technique were defined as carrying it out adequately. Table 5 shows the change in the proportion of women performing it adequately between first and second interviews for each district. There was no statistically significant difference between districts, nor between attenders and non-attenders in the proportion with adequate scores at the first interview. There was a statistically significant improvement between the first and second interviews for those in the BSE district but not in the control district. Within the BSE district the attenders showed a statistically significant improvement while the non-attenders did not. 
Table 4 Changes in frequency of breast self examination

\begin{tabular}{|c|c|c|c|c|c|c|c|}
\hline & \multirow[b]{2}{*}{$\begin{array}{l}\text { Total monthly } \\
\text { at 1st interview } \\
(\%)\end{array}$} & \multirow[b]{2}{*}{$\begin{array}{l}\text { Total monthly } \\
\text { at } 2 \text { nd interview } \\
(\%)\end{array}$} & & \multicolumn{4}{|c|}{ Change in frequency between first and second interview } \\
\hline & & & & $\begin{array}{l}\text { Decreased to less } \\
\text { than monthly } \\
(\%)\end{array}$ & $\begin{array}{l}\text { Maintained } \\
\text { monthly } \\
(\%)\end{array}$ & $\begin{array}{l}\text { Increased to } \\
\text { monthly } \\
(\%)\end{array}$ & No \\
\hline Control district & 39 & 45 & $\mathrm{p}<0.05$ & 7 & 32 & 13 & 594 \\
\hline BSE district & 42 & 50 & $\mathrm{p}<0.01$ & 10 & 32 & 18 & 540 \\
\hline Attenders & 45 & 51 & $\mathrm{p}<0.05$ & 12 & 33 & 18 & 278 \\
\hline Non-attenders & 38 & 49 & $p<0.05$ & 8 & 30 & 19 & 262 \\
\hline
\end{tabular}

Table 5 Changes in breast self examination technique score

\begin{tabular}{|c|c|c|c|c|c|c|c|}
\hline & \multirow[b]{2}{*}{$\begin{array}{l}\text { Total adequate } \\
\text { at } 1 \text { st interview } \\
(\%)\end{array}$} & \multirow[b]{2}{*}{$\begin{array}{l}\text { Total adequate } \\
\text { at } 2 \text { nd interview } \\
(\%)\end{array}$} & & \multicolumn{3}{|c|}{ Change in score between first and second interview } & \multirow[b]{2}{*}{ No } \\
\hline & & & & $\begin{array}{l}\text { Decreased from } \\
\text { adequate } \\
(\%)\end{array}$ & $\begin{array}{l}\text { Maintained } \\
\text { adequate score } \\
(\%)\end{array}$ & $\begin{array}{l}\text { Improved to } \\
\text { adequate } \\
(\%)\end{array}$ & \\
\hline Control district & 40 & 42 & $p>0.05$ & 11 & 29 & 13 & 594 \\
\hline BSE district & 39 & 62 & $p<0.001$ & 6 & 33 & 29 & 540 \\
\hline Attenders & 40 & 78 & $p<0.001$ & 3 & 37 & 41 & 278 \\
\hline Non-attenders & 38 & 43 & $p>0.05$ & 10 & 28 & 15 & 262 \\
\hline
\end{tabular}

Table 5 also shows the changes in the proportions carrying out BSE "adequately" between first and second interviews. More pronounced changes occurred in the BSE district than in the control district $(p<0 \cdot 001)$.

\section{COMBINED FREQUENCY AND TECHNIQUE}

BSE technique and frequency were then combined into one index; only those women who scored three or more points in technique and carried out BSE at least once a month were defined as doing it "satisfactorily." Table 6 shows how the proportion carrying it out "satisfactorily" showed a significant improvement between first and second interviews in the BSE district but not in the control district and among the attenders but not the non-attenders.

Table 6 also compares changes between the districts. There was a statistically significant difference $(p<0.001)$ in that more pronounced changes occurred in the BSE district than in the control district, and similarly in the attenders group compared with the non-attenders.
IDENTIFICATION OF BREAST ABNORMALITIES

At the first interview, $19 \%$ of women in the BSE district and $20 \%$ in the control district reported ever having found an abnormality (table 7). In the following year, however, slightly more in the BSE district $(5 \%)$ discovered an abnormality compared with the control district (3\%). Twenty three per cent of the attenders reported ever having identified an abnormality compared with $16 \%$ among the non-attenders, and in the year between the two interviews $7 \%$ of the attenders found an abnormality compared with $4 \%$ of non-attenders.

The proportion of abnormalities discovered by BSE had increased over the year period among women in the BSE district but decreased in the control district. Paradoxically, however, non-attenders showed a larger increase than attenders.

The proportion of women who felt confident both about their ability to identify a breast abnormality if it was there and that they were carrying out BSE in the right way (table 8 ) increased 
Table 6 Changes in satisfactory breast self examination, frequency, and technique

\begin{tabular}{|c|c|c|c|c|c|c|c|}
\hline & \multirow[b]{2}{*}{$\begin{array}{l}\text { Total satisfatory at } \\
\text { 1st interview } \\
(\%)\end{array}$} & \multirow[b]{2}{*}{$\begin{array}{l}\text { Total satisfactory at } \\
\text { 2nd interview } \\
\text { (\%) }\end{array}$} & & \multicolumn{4}{|c|}{$\begin{array}{l}\text { Change in technique and frequency between } 1 \text { st and } 2 \text { nd } \\
\text { interview }\end{array}$} \\
\hline & & & & $\begin{array}{l}\text { Decreased from } \\
\text { satisfactory } \\
(\%)\end{array}$ & $\begin{array}{l}\text { Maintained } \\
\text { satisfactory } \\
(\%)\end{array}$ & $\begin{array}{l}\text { Improved to } \\
\text { satisfactory } \\
\text { (\%) }\end{array}$ & No \\
\hline Control district & 24 & 28 & $p>0.05$ & 7 & 17 & 11 & 594 \\
\hline BSE district & 28 & 41 & $\mathrm{p}<0.001$ & 8 & 20 & 21 & 540 \\
\hline Attenders & 29 & 47 & $\mathrm{p}<0.001$ & 8 & 21 & 26 & 278 \\
\hline Non-attenders & 27 & 33 & $p>0.05$ & 9 & 18 & 15 & 262 \\
\hline
\end{tabular}

Table 7 Comparison of changes in the proportion of women who reported detecting breast abnormalities and changes in the proportion of abnormalities discovered by breast examination.

\begin{tabular}{|c|c|c|c|c|}
\hline \multirow[b]{3}{*}{$\begin{array}{l}\text { Control } \\
\text { district }\end{array}$} & \multicolumn{2}{|c|}{$\begin{array}{l}\text { \% Who reported having } \\
\text { identified a breast } \\
\text { abnormality }\end{array}$} & \multicolumn{2}{|c|}{$\begin{array}{l}\text { \% Who discovered } \\
\text { abnormality by BSE }\end{array}$} \\
\hline & 1st & $\begin{array}{l}\text { view } \\
\text { 2nd }\end{array}$ & 1st & $\begin{array}{l}\text { view } \\
\text { 2nd }\end{array}$ \\
\hline & $\begin{array}{c}20 \% \\
n=738\end{array}$ & $\begin{array}{c}3 \% \\
\mathrm{n}=594\end{array}$ & $\begin{array}{c}45 \% \\
\mathrm{n}=150\end{array}$ & $\begin{array}{c}41 \% \\
\mathrm{n}=17\end{array}$ \\
\hline$\underset{\text { district }}{\text { BSE }}$ & $\begin{array}{c}19 \% \\
\mathrm{n}=678\end{array}$ & $\begin{array}{c}5 \% \\
\mathrm{n}=540\end{array}$ & $\begin{array}{c}36 \% \\
\mathrm{n}=128\end{array}$ & $\begin{array}{c}53 \% \\
n=28\end{array}$ \\
\hline Attenders & $23 \%$ & $7 \%$ & $40 \%$ & $56 \%$ \\
\hline Non-attenders & $16 \%$ & $4 \%$ & $28 \%$ & $50 \%$ \\
\hline
\end{tabular}

Table 8 Changes in women's beliefs about their ability to practise breast self examination appropriately and effectively

\begin{tabular}{|c|c|c|c|}
\hline & & \multicolumn{2}{|l|}{ BSE district } \\
\hline & & Attenders & Non-attenders \\
\hline \multirow{2}{*}{$\begin{array}{l}\text { Confident that they can } \\
\text { detect an abnormality } \\
\text { if there }\end{array}$} & 1st interview & $206(75 \%)$ & $173(83 \%)$ \\
\hline & 2nd interview & $250(95 \%)$ & $180(96 \%)$ \\
\hline \multirow{2}{*}{$\begin{array}{l}\text { Confident that they } \\
\text { carry out BSE in the } \\
\text { right way }\end{array}$} & 1st interview & $206(55 \%)$ & $173(62 \%)$ \\
\hline & 2nd interview & $250(92 \%)$ & $180(77 \%)$ \\
\hline
\end{tabular}

among attenders to a greater extent than among non-attenders; however, more of the latter were confident about both aspects at the first interview.

\section{BELIEFS ABOUT THE VALUE OF BSE}

Table 9 shows that more women increased their score on perceived value of BSE between the two interviews in the $\mathrm{BSE}$ district than in the control district, $(\mathrm{p}<0.01)$ but within the BSE district more non-attenders increased their score (46\%) than attenders (36\%). More attenders showed a decrease in score, and the difference in the changes between the attenders and non-attenders was statistically significant $(p<0.025)$.

Table 9 Changes in women's beliefs about breast self examination between first and second interviews

\begin{tabular}{|c|c|c|c|c|}
\hline & $\begin{array}{l}\text { Attenders } \\
(\%)\end{array}$ & $\begin{array}{l}\text { BSE district } \\
\text { Non-attenders } \\
(\%)\end{array}$ & $\begin{array}{l}\text { Total } \\
(\%)\end{array}$ & $\begin{array}{l}\text { Control } \\
(\%)\end{array}$ \\
\hline \multicolumn{5}{|c|}{ Perceived value of BSE } \\
\hline Increased & 36 & 46 & 41 & 31 \\
\hline No change & 42 & 42 & 42 & 50 \\
\hline Decreased & 22 & 12 & 17 & 19 \\
\hline \multicolumn{5}{|c|}{$\begin{array}{l}\text { Images of women who } \\
\text { practise BSE }\end{array}$} \\
\hline \multicolumn{5}{|c|}{ Positive } \\
\hline 1st phase & 13 & 14 & 14 & 18 \\
\hline 2nd phase & 9 & 13 & 11 & 17 \\
\hline \multicolumn{5}{|l|}{ None } \\
\hline 1st phase & 64 & 58 & 60 & 55 \\
\hline 2nd phase & 59 & 58 & 58 & 48 \\
\hline \multicolumn{5}{|l|}{ Negative } \\
\hline \multirow{3}{*}{$\begin{array}{l}\text { 1st phase } \\
\text { 2nd phase }\end{array}$} & 23 & 28 & 26 & 28 \\
\hline & 32 & 29 & 31 & 34 \\
\hline & $\mathrm{n}=278$ & $n=262$ & $\mathrm{n}=5$ & $n=594$ \\
\hline
\end{tabular}

IMAGE OF THE PERSON WHO CARRIED OUT BSE Table 9 also shows changes in women's images of the breast self examiner and shows that whereas there was an increase in the proportion of women in each group who held some form of image there was an overall decrease in the proportion for whom it was positive and an increase in those who held a negative image. The most pronounced change occurred among the attenders when the proportion who saw the breast self examiner in a negative light increased from $23 \%$ to $32 \%$. 


\section{BELIEFS ABOUT BREAST CANCER}

Table 10 shows a comparison of changes in women's beliefs about their vulnerability to breast cancer and their concern about breast cancer, between each of the three groups. There were no statistically significant changes in perceived vulnerability between the BSE district and the control district or between the attenders and non-attenders. Changes in women's concern about breast cancer differed little between the women in the BSE district and those in the control district, although there were statistically significant differences in changes in score between the attenders and the non-attenders. More of the attenders both increased and decreased in score on concern about breast cancer compared with the non-attenders, more of whom showed no change.

Table 10 also shows there was a more pronounced increase between the first and second interviews in the proportion of women who thought that they could do something to reduce their chances of getting breast cancer among the attenders compared with the non-attenders.

Table 10 Changes in women's beliefs about breast cancer

\begin{tabular}{lllll}
\hline BSE district & & Control \\
\cline { 2 - 4 } $\begin{array}{llll}\text { Attenders } \\
(\%)\end{array}$ & $\begin{array}{l}\text { Non-attenders } \\
(\%)\end{array}$ & $\begin{array}{l}\text { Total } \\
(\%)\end{array}$ & $\begin{array}{l}\text { Control } \\
(\%)\end{array}$
\end{tabular}

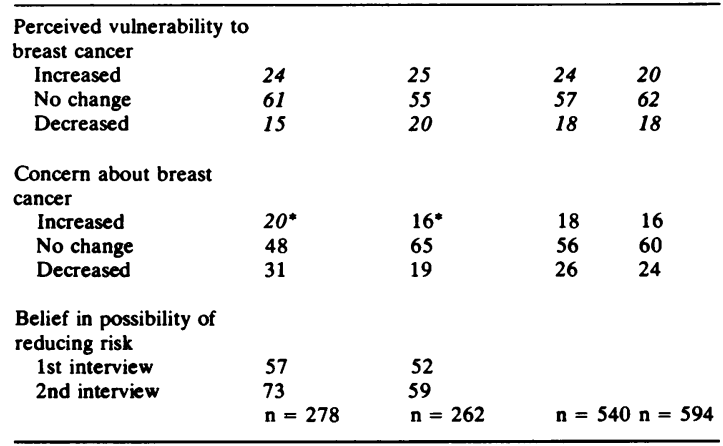

* $p<0 \cdot 001$.

\section{Discussion}

The first of the behavioural objectives of the class was achieved in that the proportion of attenders who carried out BSE satisfactorily increased by $18 \%$ which was considerably higher than the increases in non-attenders and control group. The class had a particularly pronounced effect on the technique used. These results compare favourably with the the other studies, ${ }^{5-6}$ when the most pronounced change in the practice of BSE showed a $13 \%$ increase in the proportion who carried out BSE monthly. ${ }^{3}$

With regard to enabling detection of breast abnormalities, their incidence in the year between first and second interviews in these relatively small samples of women is too low to permit firm conclusions on the efficacy of the class. The findings suggest that whereas attendance may slightly increase the likelihood of discovery of a breast abnormality it does not increase the likelihood of discovery by BSE. It could be that the class had the effect of increasing women's general awareness of the probability of finding an abnormality. Data on the proportion of abnormalities discovered from the larger population from which the sample was drawn will be available from the main trial.

The class also had some positive effects on women's beliefs about BSE in that it seemed to increase participants confidence in their ability to carry it out appropriately and effectively and also gave then a more optimistic approach to the control of breast cancer. The non-attenders, however, showed a more pronounced increase in the strength of their beliefs about the value of BSE than the attenders. This difference may be due to general publicity about BSE which had been distributed by mass media during the time invitations were being sent out. This could also account for the appreciable increase in the frequency with which BSE was carried out among non-attenders. The combination of publicity and the invitation may have had the general effect of increasing awareness about breast self examination in the BSE district, encouraging women to do it more frequently. In addition, the class itself may have had a qualitative effect in giving essential information about BSE technique and what to do if an abnormality was found.

On the more negative side, the class seemed to have the effect of both increasing some women's concern about breast cancer and decreasing others. This suggests that even with such a crude measure there is a likelihood that the class might raise some women's anxiety. The implications of this should be considered further, particularly in relation to its influence on the women's motivation to seek professional care after finding an abnormality.

It seems reasonable to conclude that a class teaching BSE is a valuable method for improving technique, although further evidence is needed on how long the education "effect" lasts and what, if anything, is required to maintain the improvement. Further research is also required on which element in the practice of $\mathrm{BSE}$ is more important in the identification of abnormalities. If frequency is shown to be more important than technique then, according 
to the results presented here, only health education through the media may be necessary.

We thank Professor R Blamey and his staff from the BSE district and Dr R Buttery and Mrs S Davies from the control district for their help in organising this study. We are grateful to social and community planning research for providing their team of interviewers. We also thank the general practitioners in both districts for permission to approach women on their lists, and most of all the women themselves for giving two interviews. The study was supported by a grant from the Department of Health and Social Security.

\section{References}

${ }^{1}$ UK Trial of Early Detection of Breast Cancer Group. Trial of early detection of breast cancer: description of method. Br J Cancer 1981; 44: 618-27.

${ }^{2}$ Green WL, Robers B J. The research literature on why women delay seeking medical care for breast symptoms. Health Education Monographs 1974: 2: 129-77.

${ }^{3}$ Hill D, Rossaby J, Gray N. Health education about breast cancer using television and doctor involvement. Prev Med 1982; 11: 43-55.

${ }^{4}$ Stillman M. Health beliefs about breast cancer and breast self examination. Nursing Research 1977: 26: 121-5.

${ }^{5} \mathrm{Hobbs} \mathrm{P}$. Evaluation of a teaching programme on breast self-examination. Int J Health Educ 1971: 4: 189-95.

${ }^{6}$ Turner J, Blamey R, Irwin G, Olding-Smee W, Roy D. Do patients read breast self-examination booklets? Health Education Journal 1981; 40: 1-12. 